\title{
Laparoscopic extraperitoneal hernioplasty of incisional hernia
}

\author{
Emad M Salah
}

Department of Surgery, Zagazig University, Egypt.

\begin{abstract}
Laparoscopic repair of incisional hernias involves intraperitoneal placement of a mesh, which may lead to adhesion formation and fistulation.The creation of a wide peritoneal flap around the hernial defect helps in placement of a mesh extraperitoneal .

The aim of this study is to determine the feasibility and effectiveness of laparoscopic extraperitoneal repair of incisional hernia.

Methods: Between June 2007 to May 2009, 47 patients 21 males and 26 females, the age range 23-55 years (mean age 45.8 years) presenting with incisional hernia underwent attempted laparoscopic incisional hernia repairs with a tension free transabdominal preperitoneal mesh repair.

Results: Mean operative time was 110 minutes (range from 85 to $165 \mathrm{~min}$.). The mean postoperative hospitalization was 1.2 days (range from 1 to 3 days). Conversion of the laparoscopic procedure to conventional open repair occurred in two patients (4.2\%). The number of hernial defects found during operation ranged from one to three, with an average of 1.4 defects per patient. The diameters of the hernial defects varied from 5 to $10 \mathrm{~cm}$, with a mean diameter of $6.2 \mathrm{~cm}$. There were no visceral or other intraoperative complications. The follow-up period was calculated from the date of operation and ranged from 2 to 24 months with a mean of 13 months. Recurrence rate occurred in one patient only $(2.1 \%)$ and was detected 13 months postoperative. Postoperative morbidities included wound bruising (8 patients), seroma (9 patients) which gradually resolved after one to six weeks, and prolonged suture site pain (4 patients) which gradually resolved after 8 weeks.

Conclusion: laparoscopic extraperitoneal placement of a mesh is feasible and appears to be an advance over laparoscopic intraperitoneal placement of a mesh for incisional hernias.

Key words : Laparoscopic, extraperitoneal, incisional hernia repair.
\end{abstract}

\section{Introduction:}

Incisional hernias arise following surgery through the anterolateral abdominal wall and it is estimated that $10-15 \%$ of laparotomy incisions eventually develop an incisional hernia. Wound infection complicating healing of the laparotomy wound is the main risk factor for development of an incisional hernia. ${ }^{1,2}$

Repair of incisional hernia has been a challenging surgical problem for many years. The operative technique of open repair has evolved from simple approximation of the defect, which is associated with a high incidence of recurrence, to prosthetic repair. Mesh hernioplasty of incisional hernia has been shown to achieve a superior long-term outcome. The placement of prosthetic mesh, however, requires extensive dissection of the hernia and thus increases the risk of wound complications. ${ }^{3}$

Laparoscopic incisional hernia repair (LIHR) has been gaining popularity in recent years. With the laparoscopic approach, long incisions and wide dissections can be avoided. The placement of a large mesh with adequate overlap of the defect is also facilitated. ${ }^{3-7}$

It is well-established that repair of sizeable incisional hernias with a mesh, most commonly constructed of polypropylene, is associated with significantly reduced incidence of recurrent herniation as compared to suturerepair without mesh. ${ }^{4,6}$ 
LIHR has gained sufficient popularity to be considered as a standard procedure. The security or reliability of repair, measured by the incidence of recurrent herniation, in mainly retrospective, selected-institution series of open repair versus LIHR has been extensively reviewed. Definitive comparison is difficult because of heterogeneity in case-mix and technique as well as length and accuracy of follow-up but, overall, LIHR appears to be at least as secure as open mesh repair. The wellestablished benefits of a minimally invasive approach, such as quick post-operative recovery and decreased risk of wound infection, favor the continuing increase in practice of LIHR. ${ }^{7-9}$

The aim of this study is to determine the feasibility and effectiveness of laparoscopic transabdominal extraperitoneal repair of incisional hernia.

\section{Patients and methods:}

Between June 2007 to May 2009, 47 consecutive patients, 21 males and 26 females, the age range 23-55 years (mean age 45.8 years) presenting with incisional hernia underwent attempted laparoscopic incisional hernia repairs with a tension free transabdominal preperitoneal mesh repair in Zagazig Universty Hospital. Selection criteria for laparoscopic incisional hernioplasty included medical fitness for general anaesthesia and absence of coagulopathy.

\section{Technique:}

The procedure was performed under general anesthesia. A nasogastric tube was placed to decompress the stomach, the patient was operated in a supine position for patients with midline incisional hernias, but in patients with lumbar hernias the patient was placed in modified flank position with a 60 degree elevation of the side ipsilateral to the hernia and lumbar roll in place. The bottom leg was flexed to 45 degree while the upper leg was kept straight and a pillow was placed between the legs. The patient was secured to the operating table with safety belts. Pneumoperitoneum was established by veress needle through the palmars point (left subcostal midclavicular line at the lateral edge of the rectus abdominus muscle) until a pressure of $15 \mathrm{~mm} \mathrm{Hg}$ was reached. The first 10-mm trocar was placed over the left anterior axillary line midway between the costal margin and the anterior superior iliac spine. A 30 degree telescope was introduced for diagnostic laparoscopy. Two working ports, a 5-mm and $10 \mathrm{~mm}$ trocars were placed over the left upper and left lower quadrants of the abdomen 10 $\mathrm{cm}$ from the hernia. Lysis of adhesions was performed using endo-scissors with bipolar diathermy or ligasur or harmonic Figure(3). The contents of the hernia were then reduced into the peritoneal cavity. After complete reduction of the contents the margin of the hernial defect was clearly defined Figure(4), the lower peritoneal flap was developed at least $5 \mathrm{~cm}$ of clearance around the hernial defects achieved Figure(5) and the upper peritoneal flap was created at least $5 \mathrm{~cm}$ above the hernial defect Figure(6). This way of development of peritoneal flaps helps in covering the mesh entirely making it completely extraperitoneal .The edges of the hernial defect were closed by interrupted intracorporeal prolene suture no.1 Figure(7). A prolyne mesh was cut to a size that would overlap the defect by at least $5 \mathrm{~cm}$ in all directions. Non-absorbable sutures were placed and tied at 5-cm intervals along the edge of the mesh. The sutures were cut to leave two tails, each at least $10 \mathrm{~cm}$ long. The mesh was then inserted into the peritoneal cavity. Multiple stab skin incisions of $2 \mathrm{~mm}$ in length were made with a scalpel along the circumference of the mesh, which had been marked on the abdominal wall. A Gore Suture Passer Instrument was inserted through the abdominal wall into the peritoneal cavity $\operatorname{Figure}(\mathbf{8})$. This was used to grasp the sutures of the mesh under direct vision and pull them through the abdominal wall. The sutures were then tied extra-corporeally and buried subcutaneously. Reperitonealization by replacing the peritoneal flaps created earlier was performed by continuous intracorporeal suturing thus making the mesh entirely extraperetoneal Figure(9). 


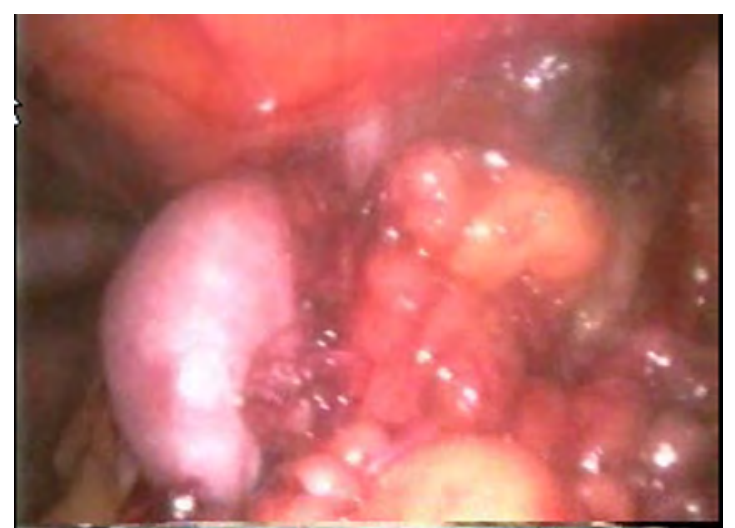

Figure (1): Hernial defect contain transverse colon and greater omentum.

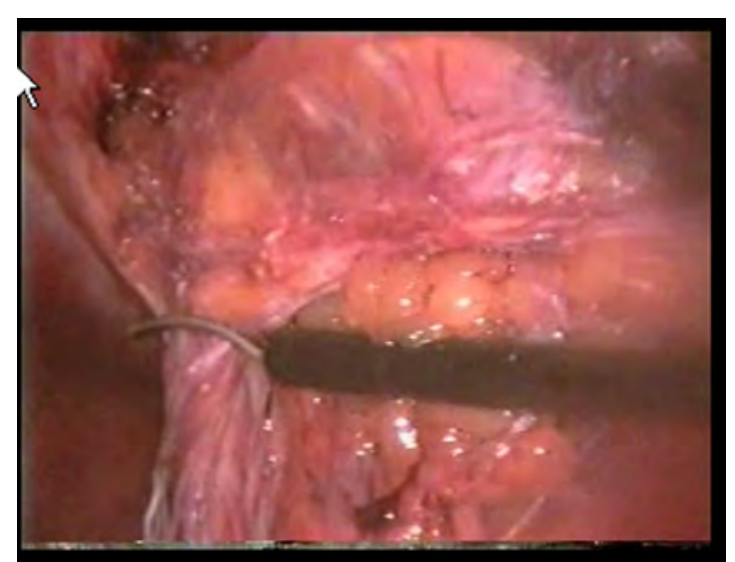

Figure (3): Reduction of the greater omentum.

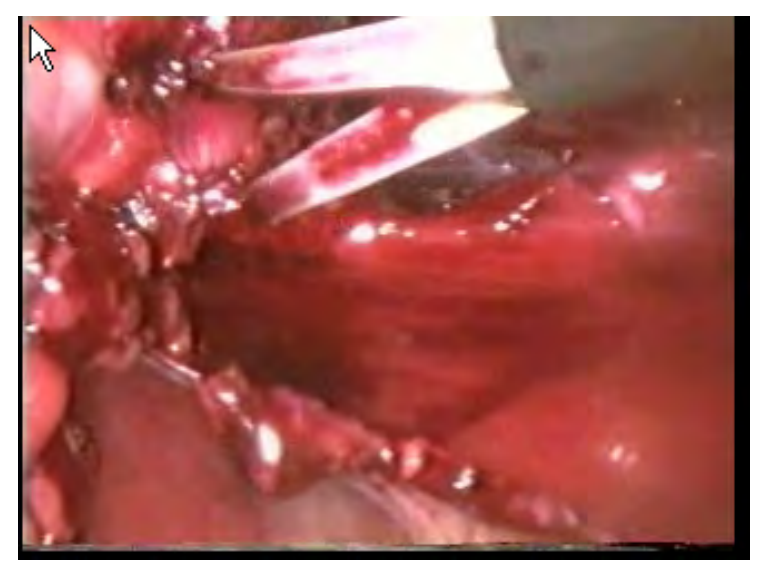

Figure (5): Creation of lower peritoneal flap.

\section{Results:}

Between June 2007 to May 2009, 47 patients. 26 females $(56.7 \%)$ and 21 males

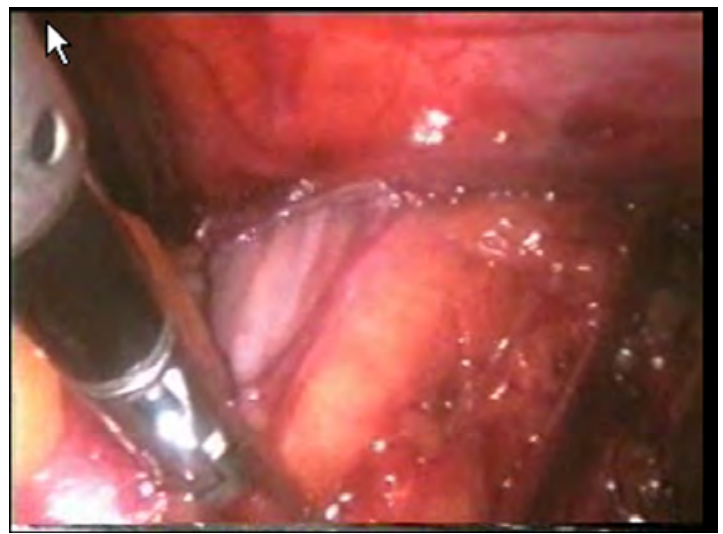

Figure (2): Reduction of the transverse colon.

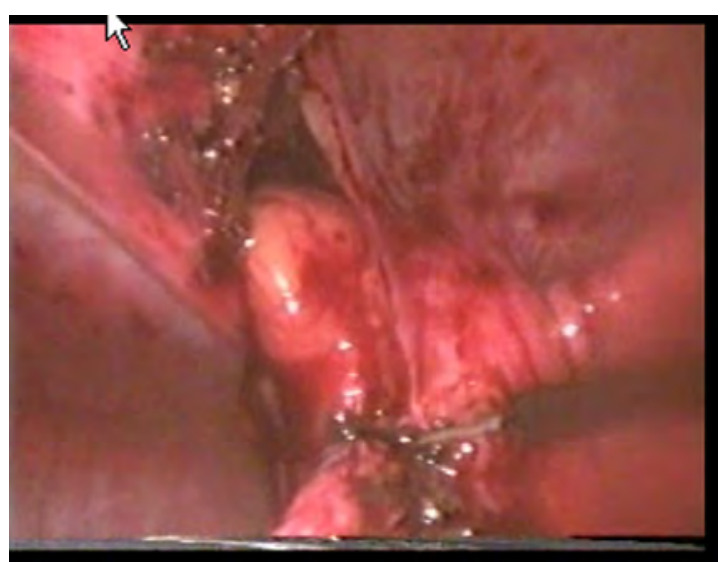

Figure (4): Complete reduction of hernial contents.

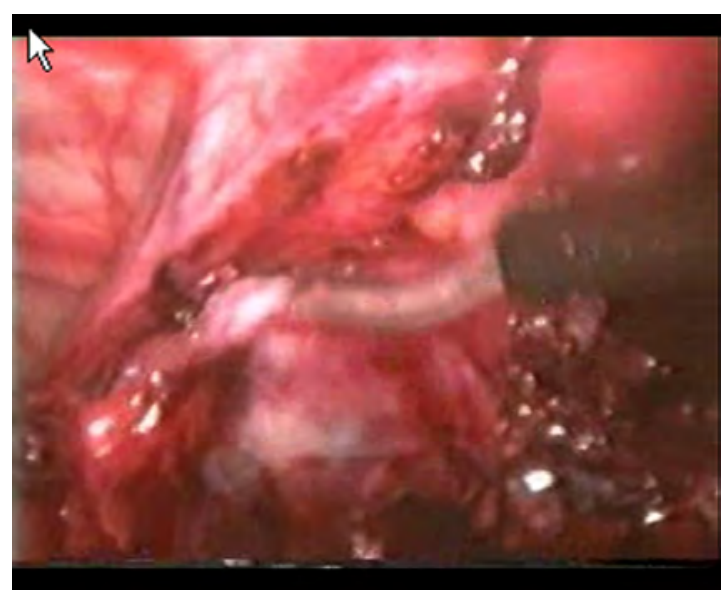

Figure (6): Creation of upper peritoneal flap.

$(44.3 \%)$ were included in the study. The age ranged from 23 to 55 year, the mean age group of the patients was 45.8 year. 


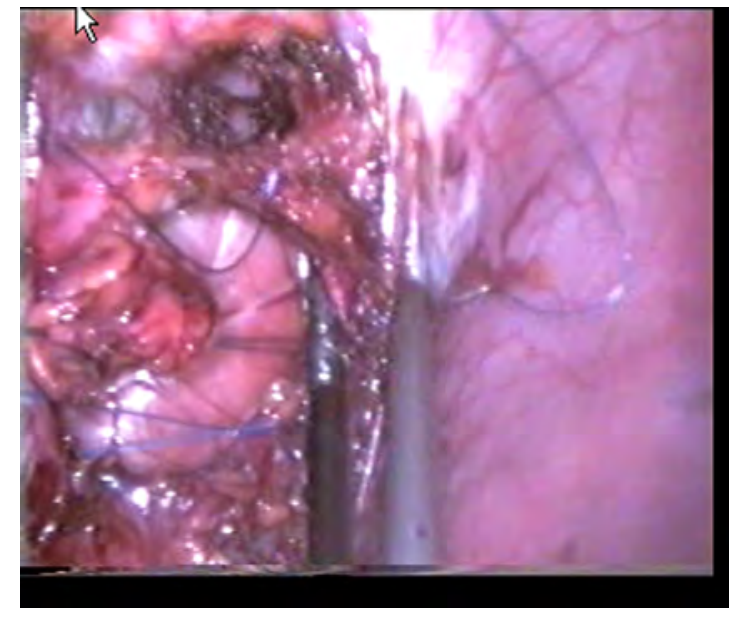

Figure (7): Closure of the hernial defect.

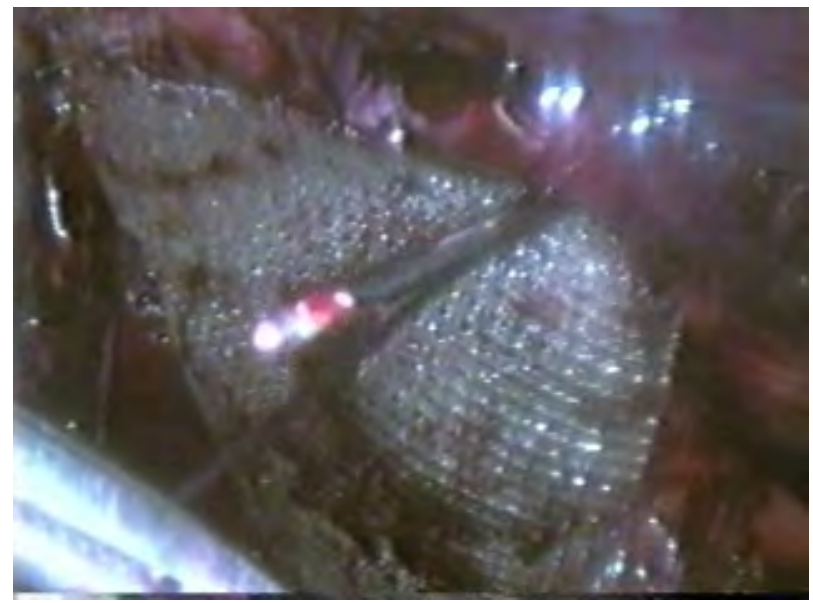

Figure (8): Fixation of the mesh extraperitoneal.

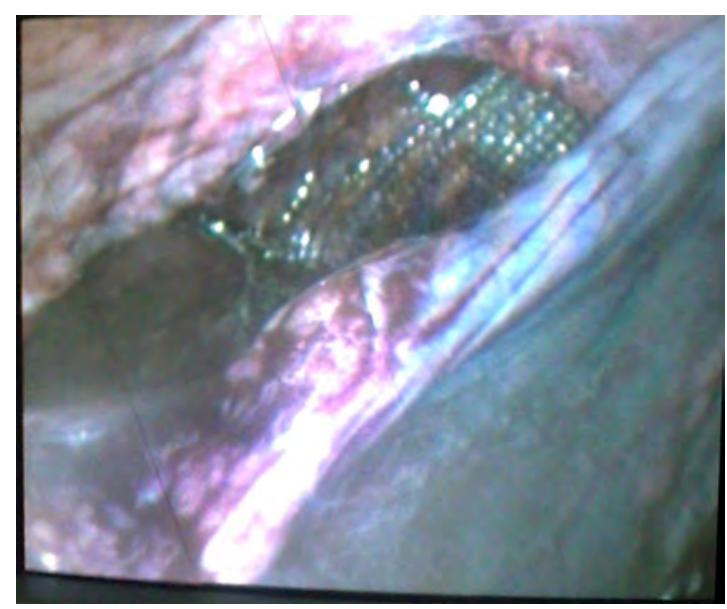

Figure (9): Reperitonealzation of the mesh.

Previous operations leading to the development of incisional hernia included splenectomy through left paramedian incision (5 patients), cholecystectomy with common bile duct exploration through upper right paramedian incision (2 patients), resection of gastric stromal tumor through midline incision (2 patients), nephrectomy through lumbar incision (2 patients), nephrolithotomy through lumbar incision (6 patients), appendicectomy through McBurneys incision (4 patients), right hemicolectomy through lower right paramedian incision (2 patients), vagotomy and gastrojujnostomy for treatment of puptic ulcer through midline incision (5 patients) and previous open repair of para-umbilical hernia (19 patients).

The mean size of the prolene mesh was $206 \mathrm{~cm}^{2}$ (range 17-235 $\mathrm{cm}^{2}$ ).

The mean abdominal wall defect in our study was $87.8 \mathrm{~cm}$ (range $59-165 \mathrm{~cm}^{2}$ ).
Mean operative time was 110 minutes (range from 85 to $165 \mathrm{~min}$.). At the beginning of the study the duration was longer but as we gained confidence the operative time became shorter.

The postoperative hospitalization was shorter, range from one to 3 days, the mean postoperative hospitalization was 1.2 days.

All the patients in the series were operated on as elective cases. Laparoscopic incisional hernioplasty was successfully performed for 45 patients, giving an overall success rate of $95.8 \%$. Two (4.2\%) patients were converted to open repair because of extensive adhesions within the peritoneal cavity.

The number of hernial defects found during operation ranged from one to three, with an average of 1.4 defects per patient. The diameters of the hernial defects varied from 5 to $10 \mathrm{~cm}$, with a mean diameter of $6.2 \mathrm{~cm}$. There were no visceral or other intraoperative complications. 
The follow-up period ranged from 2 to 24 months with a mean of 13 months. Recurrence rate occurred in one patient $(2.1 \%)$ had been detected 13 months postoperatively.

Postoperative morbidities included wound bruising (8 patients), seroma (9 patients) which gradually resolved after one to six weeks. The seromas were not aspirated and were allowed to resolve spontaneously. Prolonged suture site pain (4 patients), gradually resolved after 8 weeks.

\section{Discussion:}

Laparoscopic approach was a safe and efficacious technique for the repair of incisional hernia. Medium-term outcomes were promising with low postoperative morbidity and recurrence rates. This technique allows clear identification of multiple hernial defects and confers the advantages of minimal access surgery. ${ }^{9}$

The mean operative time was $110 \mathrm{~min}$, this is nearly same as Pham et al, ${ }^{10}$ Julian et al, ${ }^{6}$ Yuri et al, ${ }^{5}$ Sharma et al, ${ }^{11}$ Kannan and Ravintharan ${ }^{12}$ and Pradeep et al ${ }^{13}$ (108 min, 115 min, 119 min, 117 min, 120 min, 102 min and 101 min respectively). But Edwards et al, ${ }^{7}$ Marcos et al ${ }^{14}$ and Laannis et al ${ }^{15}$ reported longer operative times $144 \mathrm{~min}, 145 \mathrm{~min}$ and $132.7 \mathrm{~min}$ respectively, this is due to operating on large size hernia and presence of extensive adhesions. On the other hand Hilling et al, 16 Antinori et al, ${ }^{17}$ Karl and Le Blanc, ${ }^{18}$ Carbajo et al ${ }^{19}$ Bageaceu et al, ${ }^{20}$ and Berger et al ${ }^{21}$ reported shorter operative times $(85.6 \mathrm{~min}$, $76.1 \mathrm{~min} 88.2 \mathrm{~min}, 89 \mathrm{~min}, 85 \mathrm{~min}$, and 87.5 min respectively), this was due to intraperetoneal mesh repair.

In this study 2 patients $(4.2 \%)$ were converted to conventional open repair. This is hand by hand with Juliane et al, ${ }^{6}$ Yuri et al, ${ }^{5}$ Franklin et $\mathrm{al}^{22}$ and Ben Haim et al, ${ }^{23}$ who reported $(3.1 \%, 3 \%, 3.9 \%$, and $4 \%$ respectively). But Edwards et al, ${ }^{7}$ Pham et al, ${ }^{10}$ Kannan and Ravintharan, ${ }^{12}$ Berger et $\mathrm{al}^{21}$ and Frontzides et al ${ }^{24}$ reported no conversion to open repair. On the other hand Marcos et al ${ }^{14}$ and Laannis et al ${ }^{15}$ reported higher incidence of conventional open repair $(7.3 \%$ and $8.2 \%$, respectively). This is due to operating on large size hernia and presence of extensive adhesions.
In our study the mean hospital stay was 1.2 days. This matched with Carlsen et al, ${ }^{9}$ Stephen et al, ${ }^{25}$ Yuri et al, ${ }^{5}$ Kannan and Ravintharan, ${ }^{12}$ Karl and Le Blance ${ }^{18}$ and Julian et al ${ }^{6}$ who reported 1.6 days, 2.1 days, 1.2 days, 1.3 days, and 1.1 days respectively. But Kennealey et $\mathrm{a}^{26}$ and Karl and Le Blanc ${ }^{18}$ reported longer hospital stay, 4.3 days and 4.8 days respectively. This is due to high post operative morbidity.

The mean abdominal wall defect in our study was $79.8 \mathrm{~cm}$. This is same as Evangelos et $\mathrm{al},{ }^{4} \mathrm{Karl}$ and Le Blance, ${ }^{18}$ Laannis et al, ${ }^{15}$ Franklin et $\mathrm{al}^{22}$ and Chelala et al ${ }^{27}$ who reported $83.6 \mathrm{~cm}, 89 \mathrm{~cm}, 87.4 \mathrm{~cm}, 78.9 \mathrm{~cm}$ and $76.8 \mathrm{~cm} \%$ respectively. But Sanchez et al ${ }^{28}$ and Aura et $\mathrm{al}^{29}$ reported smaller wall defects $(26.5 \mathrm{~cm}$ and $65 \mathrm{~cm}$ respectively). On the other hand Edwards et al, ${ }^{7}$ Marcos et al, ${ }^{14}$ Laannis et al, ${ }^{15}$ Bageaceu et al, ${ }^{20}$ Berger et al, ${ }^{21}$ Carbajo et al ${ }^{19}$ and Franklin et $\mathrm{al}^{22}$ reported larger wall defects $(188 \mathrm{~cm}, 280.6 \mathrm{~cm}, 291.3 \mathrm{~cm}, 150 \mathrm{~cm}, 270.2$ $\mathrm{cm}, 200 \mathrm{~cm}$ and $384 \mathrm{~cm}$ respectively).

The mean postoperative seroma in our study occurred in $4.2 \%$. This is same as reported by Edwards et al, ${ }^{7}$ Chinnaswany et al, ${ }^{30}$ Franklin et al, ${ }^{22}$ Chelala et al, ${ }^{27}$ and Heniford et al ${ }^{31}$ who reported $2.9 \%, 2.8 \%, 5 \%, 3.1 \%$ and $2.6 \%$ respectively. But Kennealey et al, ${ }^{26}$ Sanchez et al, ${ }^{28}$ Carbajo et al ${ }^{19}$ and Bageaceu et al ${ }^{20}$ reported higher incidence of seroma $(72 \%$, $11.8 \%, 16 \%$ and $9.3 \%$ respectively). The lower incidence of seroma occurred in our study due to closure of hernial defects.

The type of mesh in our study was prolyne mesh through extraperitoneal approaches. This is similar to Chinnaswany et al 2006, Sharma et al 2005 and Pradeep et al 2003. On the other hand Lau et al 2002, Laannis et al 2003 and Stephen et al 2008 used polytetrafluoroethylene mesh but Evangelos et al 2008 used Gore-Tex mesh through intraperitoneal approaches.

The recurrence rate in this study was $2.1 \%$. This is same as reported by Evangelos et al, ${ }^{4}$ Stephen et al, ${ }^{25}$ Chinnaswany et al, ${ }^{30}$ Sharma et $\mathrm{al}^{11}$ and Pradeep et al ${ }^{13}$ who reported (2.8\%, $1.4 \%, 3.1 \%, 2.2 \%$ and $1.4 \%$ respectively). But Marcos et al, ${ }^{14}$ Bageaceu et al, ${ }^{20}$ Le-Blance et $\mathrm{al}^{32}$ and Laannis et al ${ }^{15}$ reported higher recurrence rates $(16 \%, 6.5 \%, 9 \% 12.3 \%$ and $9.3 \%$ respectively). 


\section{Conclusion:}

Laparoscopic extraperitoneal placement of a mesh is feasible and appears to be an advance over laparoscopic intraperitoneal placement of a mesh for incisional hernias. Covering a prolyn mesh with peritoneum appears to confer the advantages of reduced adhesion formation and avoidance of possible bowel herniation through the space between the mesh and peritoneum in intraperitoneal mesh. The disadvantages of laparoscopic extraperitoneal placement of a mesh are the increased dissection and operative time.

\section{References:}

1 - Wang SY, Kingsnorth AN : Prevention and surgical management of incisional hernias. Int J Surg Investig 2001; 3: 407-414.

2- Olmi S, Scaini A, Cesana G: Laparoscopic versus open incisional hernia repair: An open randomized controlled study. Sur Endosc 2007; 21: 555-559.

3- Lau H, Patil NG, Yuen WK, Lee F: Laparoscopic incisional hernioplasty utilizing on-lay expanded polytetrafluoroethylen dual mesh: Prospective study. Hong Kong Med J 2002; 8: 413-417.

4- Evangels C, Tsimoyiannis ME, Konstantinos E, Tsimogiannis M, George D, Hellen H: Seroma and recurrence in laparoscopic ventral hernioplasty. JSLS 2008; 12 : 51 57.

5- Yuri W, Novitsky M, William S, Cobb, MD, Kent W, Kercher M, Brent Matthews M, Ronald F, Sing D, Todd H: Laparoscopic ventral hernia repair in obese patients. Arch Surg 2006; 141: 57-61.

6- Juliane B, Lauren B, Melanie R, Joel M, Wayne S, Kenneth S: Long-term outcomes in laparoscopic vs ventral hernia repair. Arch Surg 2007; 142: 562-567.

7- Edwards C, Geiger T, Bartow K, Ramaswamy A, Fearing N, Thaler K, Ramshaw B: Laparoscopic transperitoneal repair of flank hernias: A retrospective review of 27 patients. Surg Endosc 2009; 22: 677-681.

8- Abeezar I: Controversies in laparoscopic repair of incisional hernia. $J$ Min Access Surg 2006; 2: 7-11.
9- Carlsen CG, Gaarden M, Lundhus E, Nielsen $\mathrm{J}$ : Initial experiences with laparoscopic incisional hernial repair. Ugeskr Laeger 2009; 30: 171(14): 1182-1185.

10-Pham CT, Perera CL, Watkin DS Maddern GJ: Laparoscopic ventral hernia repair: A systematic review. Surg Endosc 2009; 23(1): 4-15.

11-Sharma A, Panse R, Khullar R, Soni V, Baijal M, Chowbey PK: Laparoscopic transabdominal extraperitoneal repair of lumber hernia. J of Min Acc Surg 2005; 1: 70-73.

12-Kannan, Ravintharan: Laparoscopic ventral hernia Repair: Local experience. Singapore Med J 2004; 45(6): 271-275.

13-Pradeep K, Chowbey M, Anil S,Rajesh K, Vandana S, Manish D: Laparoscopic ventral hernia repair with extraperitoneal mesh. Surg Laparosc 2003; 13(2): 101105.

14-Marcos TM, Freddy JR, Marco TC, Roberto VJ, Eric RW: Laparoscopic treatment for incisional lumbar hernia in kidney donor: A new minimally invasive and efficient alternative. Einstein. 2005; 3(3): 195-198.

15-Laannis R, Danial V, Jubin K, Gregory K, Philip L: Comparison of open and laparoscopic prosthetic repair of large ventral hernias. JSLS 2003; 7: 227-232.

16- Hilling DE, Koppert LB, Keiizer R, Stassen LP, Oei IH: Laparoscopic correction of umbilical hernias using a transabdominal preperitoneal approach: Results of a pilot study. Surg Endosc 2008; 18: 214-218.

17-Antinori A, Moschella F, Maci E, Accetta C, Nunziata J, Magistrelli P: Immediate and long-term results after laparoscopic primary ventral hernia. Ann Ital Chir 2008; 79(6): 435-439.

18-Karl A, LeBlanc: Update of laparoscopic incisional hernia repair. Cirujano General 2005; 27(4):304-311.

19-Carbajo MA, Martin del Olmo JC, Blanco JI, Toledano M, de laCuesta C, Ferreras C: Laparoscopic approach to incisional hernia. Surg Endosc 2003; 17: 118-122. 20-Bageacu S, Blanc P, Breton C, Gonzales M, Porcheron J, Chabert M: Laparoscopic repair of incisional hernia: A retrospective study of 159 patients. Surg Endosc 2002; 16: 345-348. 
21-Berger D, Bientzle M, Muller A: Postoperative complications after laparoscopic incisional hernia repair. Incidence and treatment. Surg Endosc 2002; 16: 1720-1723.

22- Franklin ME, Gonzales JR, Glass JL, Manjarrez A: Laparoscopic ventral and incisional hernia repair: An 11-year experience. Hernia 2004; 8: 23-27.

23-Ben-Haim M, Kuriansky J, Tal R, Zmora O, Mintz Y, Rosin D: Pitfalls and complications with laparoscopic intraperitoneal expanded polytetraflurorethylen patch repair of postoperative ventral hernia. Surg Endosc 2002; 16: 785-788.

24-Frantzides CT, Carlson MA, Zografakis JG, Madan AK, Moore RE: Minimally invasive incisional herniorrhaphy: A review of 208 cases. Surg Endosc 2004; 18: 14881491.

25-Stephan F, Jamie W, Christopher N: Transperitoneal laparoscopic repair of a dorsal lumbotomy incisional hernia. Can Urol Assoc J 2008; 2: 139-142.

26-Kennealey PT, Johnson CS, Tector AJ, Selzer DJ: Laparoscopic incisional hernia repair after solid-organ transplantation. Arch Surg 2009; 144(3): 228-233.
27-Chelala E, Gaede F, Douillez V, Dessily $\mathrm{M}$ and Alle JL: The suturing concept for laparoscopic mesh fixation in ventral and incisional hernias: preliminary results. Hernia 2003; 7: 191-196.

28-Sanchez LJ, Bencini L, Moretti R: Recurrences after laparoscopic ventral hernia repair: Results and critical review. Hernia 2004; 8: 138-143.

29-Aura T, Habib E, Mekkaoui M, Brassier D, Elhadad A: Laparoscopic tension-free repair of anterior abdominal wall incisional and ventral hernias with an intraperitoneal Gore-Tex mesh: Prospective study and review of the literature. J Laparoendosc Adv Surg Tech A 2002; 12: 263-267.

30-Chinnaswamy P, Malladi V, Kalpeshv J D, Pidigue S, Subbiah R: Laparoscopic transabdominal pereperitoneal repair of spigelian hernia. JSLS 2006; 10: 193-198. 31-Heniford BT, Park A, Ramshaw BJ, Voeller G: Laparoscopic repair of ventral hernias: Nine yearsí experience with 850 consecutive hernias. Ann Surg 2003; 238: 391-399.

32- LeBlanc KA, Whitaker JM, Bellanger DE, Rhynes VK: Laparoscopic incisional and ventral hernioplasty: Lessons learned from 200 Patients. Hernia 2003; 7: 118-124. 